\title{
A simple neural autism model based on sensory invariants
}

\author{
N M Mayer ${ }^{1 *}$, lan Fasel $^{2}$ \\ From Nineteenth Annual Computational Neuroscience Meeting: CNS*2010 \\ San Antonio, TX, USA. 24-30 July 2010
}

Autistic individuals show a variety of curious behavioral and perceptual patterns which generally seem to lack a common underlying cause. We propose a theory of learning and perception which suggests that the general impairment of the autistic brain may be a restriction on the class of connectivity patterns (or 'features') that can be utilized for learning perceptual and cognitive tasks. In particular, we argue that the autistic brain does not make proper use of features which pool information over larger areas of the input space, which would allow them to make use of symmetries and develop invariants to permutations. We present preliminary findings with a simple neuronal model which provides useful analogies to psycho-physical experimental findings in support of this hypothesis.

Our model consists of a two layer perceptron model. 'Neurons' in the model are connectionist neurons, thus are not meant to represent real biological neurons but rather functional entities that serve our task. In the first layer we have a set of model neurons with fixed random receptive fields. The second neuron layer learns by quadratic optimization to discriminate a noisy "smiley face" from a non-smiling face placed at random locations within the visual field. The only difference between

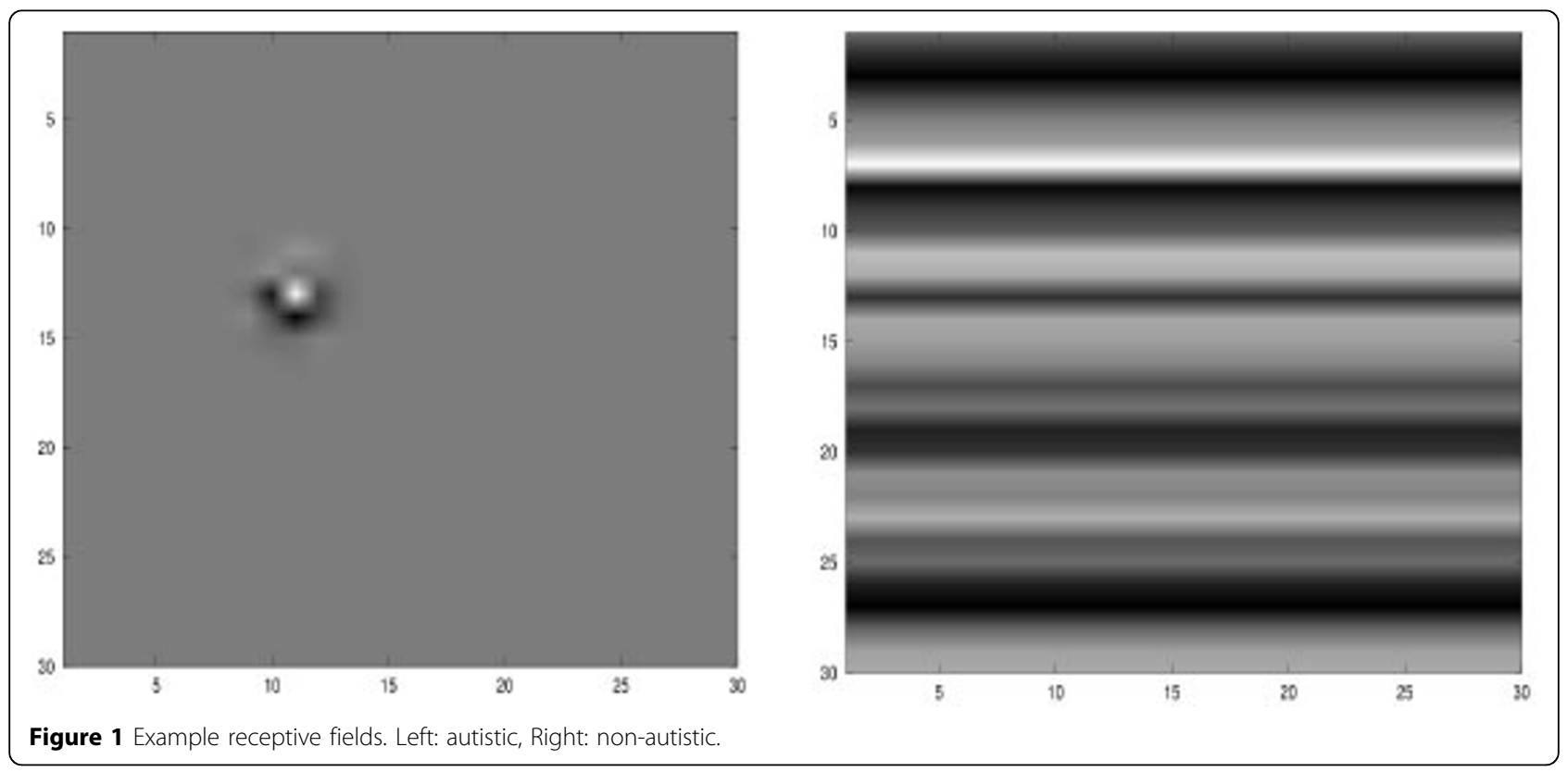

* Correspondence: mikemayer@ccu.edu.tw

'Department of Electrical Engineering, National Chung Cheng University, Chia-Yi, Taiwan 

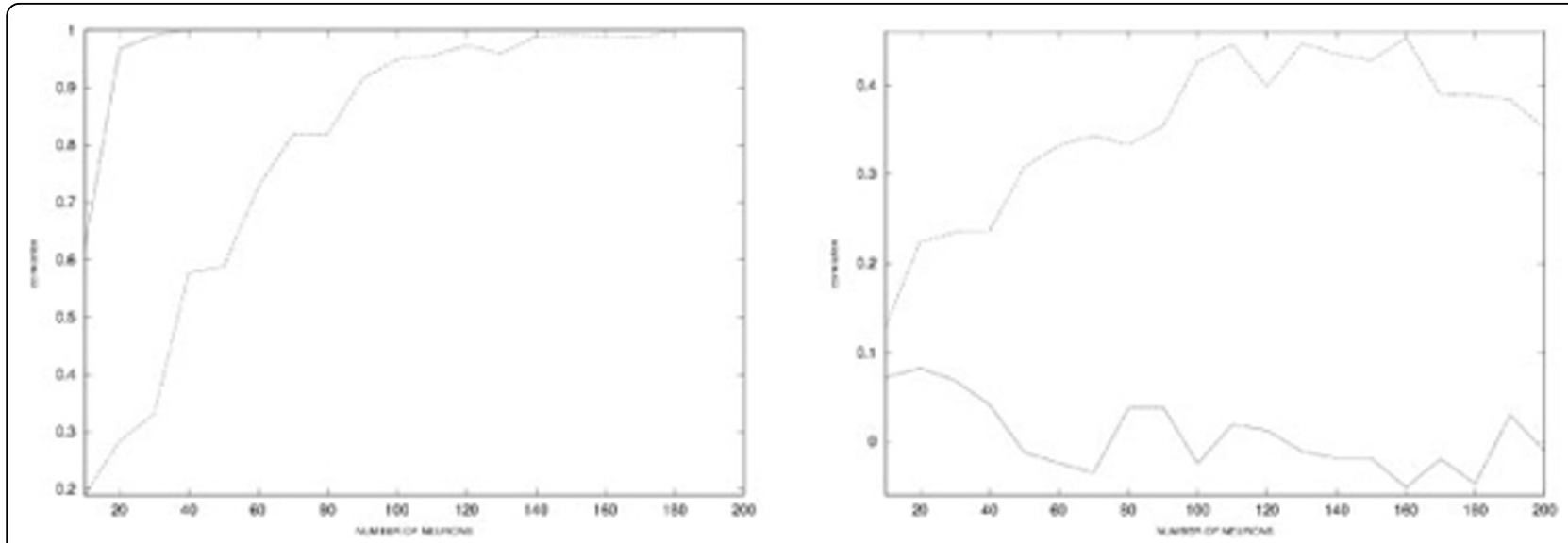

Figure 2 Left: Discrimination error (y-axis) versus number of neurons (x-axis) for both non-autistic (full line) and autistic model (dashed). In both types the error reduces with the number of neurons, the non-autistic type shows a better performance. Right: In the case of a test set with an incomplete smiley, the correlation between the neuronal response was tested versus the model type and the number of neurons. Here the autistic model shows better performance than the non-autistic model.

the autistic and non-autistic version of the model is the shape of the receptive fields - autistic neurons have circular receptive fields while non-autistic neurons have horizontal receptive fields. As shown in Figure 2, the non-autistic version is able to solve the discrimination task with a much smaller number of neurons in the first layer. However if the "smiley face" is presented only partly to the model, the autistic version is actually better at the discrimination task then the non-autistic version of the model. This coincides -among other parallels to psycho-physical experiments- with findings in which autistic children show better performance in recognizing faces from parts [1].

\section{Acknowledgments}

We thank M. Asada and M. Ogino for helpful hints and discussions.The work has been supported by National Science Council grant number 98-2218-E194-003 -MY2.

\section{Author details}

'Department of Electrical Engineering, National Chung Cheng University, Chia-Yi, Taiwan. ${ }^{2}$ Department of Computer Science, University of Arizona, USA.

Published: 20 July 2010

\section{Reference}

1. Langdell T: Recognotion of faces: an approach to the study of autism. $J$ Child Psychol Psychiatry 1978, 19:255-268.

doi:10.1186/1471-2202-11-S1-P79

Cite this article as: Mayer and Fasel: A simple neural autism model based on sensory invariants. BMC Neuroscience 201011 (Suppl 1):P79.
Submit your next manuscript to BioMed Central and take full advantage of:

- Convenient online submission

- Thorough peer review

- No space constraints or color figure charges

- Immediate publication on acceptance

- Inclusion in PubMed, CAS, Scopus and Google Scholar

- Research which is freely available for redistribution

Submit your manuscript at www.biomedcentral.com/submit 